\title{
Perbedaan Pola Pemberian Makan Batita Diasuh Ibu Dan Selain Ibu
}

\section{Difference of Feeding Pattern between Toddler Who Mother's and Other's Care}

Putri Novita Sari* ${ }^{1}$, Sri Sumarmi ${ }^{1}$

\begin{abstract}
ABSTRAK
Latar Belakang: Di era sekarang, wanita semakin banyak bekerja khususnya ibu, sehingga semakin banyak anak yang tidak diasuh sendiri oleh orang tuanya. Situasi ini menjadi faktor resiko terjadinya masalah gizi pada anak di daerah perkotaan. Pola pemberian makan pengasuh yang tidak tepat pada batita termasuk faktor penyebab tidak langsung terjadinya masalah gizi pada batita.

Tujuan: Tujuan penelitian untuk menganalisis perbedaan pola pemberian makan batita yang diasuh ibu dan batita yang diasuh selain ibu.

Metode: Metode penelitian ini adalah observasional dengan desain cross sectional, dan teknik pengambilan sampel menggunakan simple random sampling. Jumlah sampel penelitian adalah 74 responden. Variabel yang diukur yaitu sosial ekonomi keluarga, karakteristik pengasuh dan pola pemberian makan. Penelitian dilakukan di Kelurahan Mulyorejo, wilayah kerja Puskesmas Mulyorejo Surabaya. Analisis data menggunakan uji statistik Chi-square dengan nilai $\alpha=0,05$.

Hasil: Hasil penelitian menunjukkan tidak ada perbedaan pola pemberian makan antara batita diasuh ibu dan batita diasuh selain ibu dengan nilai $p=1,000>0,05$.

Kesimpulan: Simpulan dari hasil yaitu di daerah perkotaan, pola pemberian makan tidak hanya dipengaruhi oleh pengasuh batita tetapi beberapa faktor seperti status ekonomi keluarga..
\end{abstract}

Kata Kunci: pola pemberian makan, batita, pengasuh

\begin{abstract}
Background: In the present era, working women are increased, especially working mothers, therefore many children are not taken care by their parent. This situation may become risk factor for malnutrition among children in urban areas. Feeding pattern is indirect causes of nutritional problems in toddler.

Objectives: The objective of the study was to analyze the difference of toddler feeding pattern and nutritional status between toddler who cared by mother and toddler who cared by other caregivers. Methods: The method of this research was observational with cross sectional design, and the sampling technique used simple random sampling. The number of samples were 74 toddlers. Variables observed in this study were socio-economic status of family, characteristics of caregivers and feeding pattern. The research was conducted in Mulyorejo urban village Surabaya. The data were analyzed by Chi-square test with $\alpha=0.05$.

Results: The result of the research showed that there was no difference of feeding pattern $(p=1.000)$ between toddler who cared by mother and toddler who cared by other caregivers.

Conclusion: The conclusion from this research is in urban areas, feeding pattern is not only influenced by caregiver but also several factors such as economic status.
\end{abstract}


Keywords: Feeding Pattern, Toddler, caregiver

\author{
*Koresponden: \\ putrinovitasari0924@gmail.com \\ ${ }^{1}$ Departemen Gizi Kesehatan, Fakultas \\ Kesehatan Masyarakat-Universitas Airlangga
}

\section{PENDAHULUAN}

Di era sekarang, wanita semakin banyak bekerja khususnya ibu, sehingga semakin banyak pula anak yang ditinggal bekerja orang tuanya ${ }^{1}$. Jumlah wanita yang mencari pekerjaan tahun 2014 yaitu 626.300, dan jumlah wanita yang telah bekerja sebesar $288.614^{2}$. Di Indonesia terdapat 3 Provinsi dengan jumlah pekerja wanita paling tinggi yaitu Jawa Timur, Jawa Barat dan Jawa Tengah. Jumlah pekerja di Jawa Timur sebesar 101.922. Jumlah wanita yang mencari pekerjaan pada tahun 2014 sebesar $417.398^{3}$. Semakin banyak ibu yang bekerja maka peran sebagai ibu tidak bisa dikerjakan secara optimal.

Tahun 2013 di Kelurahan Mulyorejo jumlah wanita sebagai kepala keluarga sebesar 284 jiwa $^{4}$. Wanita yang menjadi kepala keluarga yaitu single parents. Wanita single parents berpotensi besar untuk bekerja agar bisa memenuhi kebutuhan hidup dan akhirnya melimpahkan tanggungjawab merawat anak kepada orang lain. Peran ibu adalah sebagai pengasuh anak dan pengatur konsumsi pangan anggota keluarga, terutama balita. Semakin banyak ibu rumah tangga yang bekerja, terutama mereka yang memiliki balita, maka peran sebagai ibu tidak bisa dikerjakan secara optimal ${ }^{5}$. Hal tersebut bisa menimbulkan masalah gizi balita. Ibu bekerja akan semakin sibuk dengan pekerjaannya, selain itu mengalami kelelahan fisik dan memilih beristirahat dibanding mengurus balita dan keluarga, sehingga perhatian ibu terhadap balita menjadi berkurang. ${ }^{6}$ Ibu bekerja cenderung memilih solusi praktis di tengah keterbatasan waktu yang dimiliki untuk berinteraksi dengan anak akibat tuntutan pekerjaan yang dijalani ${ }^{7}$. Ketika waktu bersama balita semakin sedikit dan berkurang, maka banyak ibu yang melimpahkan tanggung jawab pengasuhan anak kepada pengasuh lain seperti kakeknenek, tempat Penitipan Anak (TPA), pembantu, maupun baby sitter ${ }^{8}$. Beberapa penelitian terkait status pekerjaan ibu dengan status gizi balita yaitu penelitian Sulistyorini dan Rahayu menunjukkan adanya hubungan status pekerjaan ibu dengan status gizi balita, ibu tidak bekerja memiliki balita dengan status gizi lebih baik $^{5}$. Penelitian Wijaya mununjukkan adanya perbedaan status gizi balita yang diasuh ibu dan diasuh pembantu rumah tangga. Balita yang diasuh ibu memiliki status gizi lebih baik dibanding balita yang diasuh pembantu rumah tangga, hal tersebut dikarenakan kasih sayang pembantu rumah tangga terhadap balita tidak sebesar kasih sayang ibu kepada balita, sehingga pola pemberian makan pembantu rumah tangga terhadap balita kurang tepat dan mempengaruhi status gizi balita ${ }^{9}$. Penelitian Putri menjelaskan bahwa status pekerjaan ibu merupakan faktor paling dominan yang berhubungan dengan status gizi balita, yang mana status gizi dipengaruhi oleh pola pemberian makan pengasuh ${ }^{10}$.

Tahun 2013 di Kelurahan Mulyorejo jumlah balita gizi kurang 3 orang dan 1 gizi buruk. Pada tahun 2015 di kecamatan Mulyorejo terdapat 56 balita gizi kurang dan gizi buruk, akan tetapi Kelurahan Mulyorejo menduduki peringkat tertinggi yaitu 25 balita, dengan rincian gizi kurang 23 dan gizi buruk 2 orang. Hal tersebut menunjukkan adanya peningkatan balita yang mengalami masalah gizi di Kelurahan Mulyorejo dari tahun 2013 sebesar 4 balita menjadi 25 balita ditahun 2015, yang mana terjadi peningkatan signifikan sebesar $21 \%{ }^{11}$. Peningkatan masalah gizi tersebut dapat dipengaruhi berbagai faktor, seperti banyaknya wanita yang single 
parents di Kelurahan Mulyorejo sehingga mereka harus bekerja dan menitipkan anak pada orang lain. Semakin banyak ibu rumah tangga yang bekerja, terutama mereka yang memiliki balita, maka peran sebagai ibu tidak bisa dikerjakan secara optimal ${ }^{5}$, oleh karena itu hal tersebut dapat menjadi faktor resiko terjadinya masalah gizi pada balita.

Balita merupakan kelompok umur yang rawan gizi dan rawan penyakit. Masa balita merupakan masa kehidupan yang sangat penting dan membutuhkan perhatian serius $^{12}$. Pola asuh termasuk faktor penyebab tidak langsung terjadinya masalah gizi pada balita $^{13}$. Pola asuh meliputi pola pemberian makan baik jenis, kualitas serta kuantitas makanan yang diberikan sesuai dengan umur balita. Masa balita harus memperloleh asupan zat gizi dari makanan sehari-hari dalam jumlah yang tepat dan kualitas yang terjamin ${ }^{12}$. Asupan makanan balita sangat bergantung pada orang dewasa, yaitu pengasuh. Pola pemberian makan yang seimbang dan sesuai dengan kebutuhan, serta pemilihan bahan makanan yang tepat akan tercapai status gizi yang baik ${ }^{14}$.

Adapun tujuan dan manfaat dari penelitian ini adalah untuk menganalisis perbedaan pola pemberian makan batita yang diasuh ibu dan batita yang diasuh selain ibu.

\section{METODE}

Jenis penelitian yang dilakukan adalah observasional dan berdasarkan waktunya penelitian ini menggunakan desain cross sectional, karena variabel independen dan dependen pada subyek penelitian diukur pada saat yang sama ${ }^{15}$. Penelitian ini dilakukan di Kelurahan Mulyorejo, wilayah kerja Puskesmas Mulyorejo Surabaya. Populasi dalam penelitian yaitu 150 batita yang aktif mengikuti kegiatan Posyandu.

Pengambilan sampel dilakukan dengan cara Simple Random Sampling, setiap subyek dalam populasi memiliki kemungkinan yang sama untuk terpilih ${ }^{16}$. Sampel dalam penelitian ini adalah 74 batita, dan responden dalam penelitian ini adalah pengasuh batita. Penelitian ini dilakukan di Kelurahan Mulyorejo, wilayah kerja Puskesmas Mulyorejo Surabaya.
Waktu penelitian mulai bulan AprilMei 2017, dan pengumpulan data menggunakan data primer dan sekunder. Data sekunder meliputi jumlah batita, data tersebut diperoleh dari Puskesmas Mulyorejo Surabaya, selain itu juga terdapat data jumlah ibu yang bekerja dari Kelurahan Mulyorejo. Pengambilan data primer melalui wawancara terkait karakteristik pengasuh, batita dan kondisi sosial ekonomi keluarga batita, sedangkan untuk variabel pola pemberian makan menggunakan kuisioner terstruktur mengenai pola pemberian makan batita yaitu Child Feeding questionnaire yang telah divalidasi. Analisis data menggunakan uji statistic Chi-square dengan nilai $\alpha=0,05$. Sebelum pengambilan data primer, peneliti telah melakukan uji etik untuk kelayakan etika ketika pengambilan data di lapangan.

\section{HASIL DAN PEMBAHASAN}

Berdasarkan hasil penelitian tentang perbedaan pola pemberian makan batita diasuh ibu dan selain ibu di Kelurahan Mulyorejo, wilayah kerja Puskesmas Mulyorejo Surabaya, didapatkan karakteristik umum subyek penelitian yang ditunjukkan pada tabel 1.

Pada tabel 1 dapat dilihat bahwa sebagian besar batita berjenis kelamin laki-laki yaitu sebesar $59,5 \%$ yang diasuh ibu dan $54,1 \%$ diasuh selain ibu, selain itu juga menunjukkan bahwa rata-rata pendapatan keluarga batita yang diasuh selain ibu yaitu $\geq$ UMR sebesar $83,8 \%$, dan rata-rata jumlah anggota keluarga batita yang diasuh selain ibu yaitu $\leq 4$ orang sebesar $91,9 \%$. Tabel 1 juga menunjukkan usia pengasuh selain ibu yaitu $>40$ tahun sebesar $75,7 \%$ dan hubungan pengasuh dengan batita yang diasuh selain ibu yaitu rata-rata sebagai nenek sebesar $59,5 \%$.

Hasil penelitian menunjukkan bahwa tingkat pendapatan keluarga batita yang diasuh selain ibu rata-rata $\geq$ UMR sebesar $(83,8 \%)$, hal tersebut menjadi faktor tidak langsung pola pemberian makan batita. Hal tersebut didukung oleh penelitian Chelule yang menunjukkan hasil bahwa faktor ekonomi mempengaruhi pola pemberian makan, karena akan mempengaruhi ketersediaan pangan dalam rumah tangga ${ }^{17}$. 
Tabel 1. Karakteristik Batita, Orang Tua Batita dan Responden

\begin{tabular}{|c|c|c|c|c|c|c|}
\hline & \multirow{3}{*}{ Karakteristik } & \multicolumn{4}{|c|}{ Pengasuh } & \multirow{3}{*}{$P$} \\
\hline & & \multicolumn{2}{|c|}{ Ibu } & \multicolumn{2}{|c|}{ Selain ibu } & \\
\hline & & $n$ & $\%$ & $\mathbf{n}$ & $\%$ & \\
\hline \multirow{6}{*}{$\begin{array}{l}\text { Karakteristik } \\
\text { balita }\end{array}$} & Jenis kelamin & & & & & \\
\hline & Laki-laki & 22 & 59,5 & 20 & 54,1 & \\
\hline & Perempuan & 15 & 40,5 & 17 & 45,9 & \\
\hline & Usia (bulan) & & & & & \\
\hline & $12-24$ & 22 & 59,5 & 20 & 54,1 & \\
\hline & $25-36$ & 15 & 40,5 & 17 & 45,9 & \\
\hline \multirow{13}{*}{$\begin{array}{l}\text { Orang Tua } \\
\text { Batita }\end{array}$} & Pendidikan Ibu & & & & & \multirow{6}{*}{0,007} \\
\hline & Tidak Sekolah & 1 & 2,7 & 0 & 0 & \\
\hline & SD & 10 & 27 & 0 & 0 & \\
\hline & SMP & 10 & 27 & 11 & 29,7 & \\
\hline & SMA & 13 & 35,1 & 18 & 48,6 & \\
\hline & PT & 3 & 8,1 & 8 & 21,6 & \\
\hline & Pendapatan Keluarga & & & & & \multirow{3}{*}{0,000} \\
\hline & $<$ UMR & 25 & 67,6 & 6 & 16,2 & \\
\hline & $\geq$ UMR & 12 & 32,4 & 31 & 83,8 & \\
\hline & \multicolumn{5}{|l|}{ Jumlah Anggota } & \multirow{4}{*}{0,006} \\
\hline & Keluarga & & & & & \\
\hline & $\leq 4$ & 23 & 62,2 & 34 & 91,9 & \\
\hline & $5-6$ & 14 & 37,8 & 3 & 8,1 & \\
\hline \multirow{12}{*}{$\begin{array}{l}\text { Responden } \\
\text { (Pengasuh) }\end{array}$} & Usia & & & & & \multirow{5}{*}{0,000} \\
\hline & $\leq 20$ & 3 & 8,1 & 0 & 0 & \\
\hline & $21-30$ & 14 & 37,8 & 5 & 13,5 & \\
\hline & $31-40$ & 15 & 40,5 & 4 & 10,8 & \\
\hline & $>40$ & 5 & 13,5 & 28 & 75,7 & \\
\hline & $\begin{array}{l}\text { Hubungan Responden } \\
\text { dengan Batita }\end{array}$ & & & & & \multirow{7}{*}{0,000} \\
\hline & Ibu & 37 & 100 & 0 & 0 & \\
\hline & Nenek & 0 & 0 & 22 & 59,5 & \\
\hline & Kakek & 0 & 0 & 1 & 2,7 & \\
\hline & Tetangga & 0 & 0 & 2 & 5,4 & \\
\hline & Baby sitter & 0 & 0 & 5 & 13,5 & \\
\hline & Lainnya & 0 & 0 & 7 & 18,9 & \\
\hline
\end{tabular}

Tabel 2. Distribusi Pola Pemberian Makan Batita

\begin{tabular}{|c|c|c|c|c|c|}
\hline \multirow{3}{*}{$\begin{array}{c}\text { Pola Pemberian } \\
\text { Makan }\end{array}$} & \multicolumn{4}{|c|}{ Pengasuh } & \multirow{3}{*}{$P$} \\
\hline & \multicolumn{2}{|c|}{ Ibu } & \multicolumn{2}{|c|}{ Selain Ibu } & \\
\hline & $\mathbf{n}$ & $\%$ & $\mathbf{n}$ & $\%$ & \\
\hline Tepat & 33 & 89,2 & 33 & 89,2 & \multirow{2}{*}{1,000} \\
\hline Tidak Tepat & 4 & 10,8 & 4 & 10,8 & \\
\hline
\end{tabular}


Pada tabel 2 dapat dilihat bahwa ratarata pola pemberian makan batita sudah tepat, kategori pola pemberian makan dikatakan tepat jika nilai presentasenya 55\%$100 \%$, dan tidak tepat jika $<55 \%$. Pola pemberian makan sebagian besar sudah tepat, batita yang diasuh ibu dan selain ibu sebesar $89,2 \%$, akan tetapi masih ada yang tidak tepat yaitu $10,8 \%$ batita yang diasuh ibu dan $10,8 \%$ batita diasuh selain ibu.

Pola pemberian makan yang seimbang dan sesuai dengan kebutuhan, serta pemilihan bahan makanan yang tepat akan tercapai status gizi yang baik ${ }^{5}$. Pertumbuhan balita dipengaruhi kualitas makan,yang mana tergantung dari pola asuh pengasuh, sehingga akan mempengaruhi status gizi balita apabila pola pemberian makan pengasuh tidak baik ${ }^{18}$. Hal tersebut didukung oleh penelitian Kumala yang menyatakan bahwa terdapat hubungan yang bermakna antara pola pemberian makan dengan status gizi balita usia 1-3 tahun ${ }^{19}$.

Pada tabel 1 dapat dilihat bahwa ada perbedaan pendidikan ibu antara batita yang diasuh ibu dan selain ibu dengan tingkat signifikan $p<\alpha(\alpha=0,05)$. Ada perbedaan tingkat pendapatan keluarga antara batita yang diasuh ibu dan selain ibu dengan tingkat signifikan $p<\alpha(\alpha=0,05)$. Ada perbedaan jumlah anggota keluarga antara batita yang diasuh ibu dan selain ibu dengan tingkat signifikan $p<\alpha(\alpha=0,05)$. Ada perbedaan usia pengasuh antara batita yang diasuh ibu dan selain ibu dengan tingkat signifikan $p<\alpha$ ( $\alpha=$ $0,05)$. Ada perbedaan hubungan pengasuh dengan batita antara batita yang diasuh ibu dan selain ibu dengan tingkat signifikan $p<\alpha$ $(\alpha=0,05)$.

Tabel 2 menunjukkan bahwa tidak ada perbedaan pola pemberian makan antara batita yang diasuh ibu dan selain ibu, dengan tingkat signifikan $p>\alpha(\alpha=0,05)$. Hasil tersebut didukung hasil penelitian Kurniasari yang memaparkan tidak adanya perbedaan status gizi batita antara batita yang ibunya bekerja dan tidak bekerja, hal ini dikarenakan baik ibu batita yang bekerja dan tidak, samasama memiliki tingkat pendidikan tinggi dan pendapatan keluarga batita juga tinggi ${ }^{20}$.

Pola pemberian makan merupakan gambaran atau informasi mengenai asupan gizi yang meliputi jenis, porsi dan frekuensi dalam pemenuhan nutrisi ${ }^{21}$. Faktor yang mempengaruhi pola pemberian makan tidak hanya penanggungjawab mengasuh batita setiap harinya, akan tetapi dipengaruhi berbagai faktor seperti tingkat pendidikan ibu batita, tingkat pendapatan keluarga, jumah anggota keluarga, usia pengasuh dan hubungan pengasuh dengan batita ${ }^{5}$. Hasil penelitian menunjukkan bahwa tingkat pendidikan ibu, yang mana batitanya diasuh selain ibu yaitu rata-rata SMA sebesar $(58,1 \%)$, sehingga lebih mudah menerima informasi khususnya terkait gizi dan mengimplementasikannya. Pendidikan ibu yang relatif rendah juga akan berkaitan dengan sikap dan tindakan ibu dalam menangani masalah kurang gizi pada anak balitanya begitupun sebaliknya ${ }^{10}$. Hasil penelitian ini menunjukkan tidak adanya perbedaan pola pemberian makan antara batita yang diasuh ibu dan batita yang diasuh ibu, karena sebagian besar dalam kategori normal. Batita yang diasuh selain ibu, pola pemberian makan pengasuh dalam kategori tepat, hal tersebut juga dipengaruhi oleh tingkat pendidikan ibu batita yang tinggi sehingga mengetahui informasi yang baik bagi anaknya dan akan menyampaikan kepada pengasuh batitanya, sehingga informasi tersebut diaplikasikan.

Jumlah anggota keluarga batita yang diasuh selain ibu rata-rata $\leq 4$ orang sebesar (91,9\%). Jumlah anggota keluarga yang besar, akan mempengaruhi pembagian makan dalam keluarga. Didukung penelitian Tessema yang memaparkan bahwa keluarga dengan jumlah anggota $>5$ akan mempengaruhi pola pemberian makan balita karena konsumsi makanan yang tidak bervariasi ${ }^{22}$.

Usia pengasuh rata-rata $31->40$ tahun, maka lebih berpengalaman dalam merawat balita sehingga pola pemberian makan batita akan baik. Pernyataan tersebut didukung oleh penelitian Sukoco yang memaparkan bahwa, semakin muda usia pengasuh (17-25) akan mempengaruhi pola pemberian makan balita yang akan berdampak pada status gizi kurang ${ }^{23}$. Hasil penelitian menunjukkan usia pengasuh selain ibu sebagian besar $>40$ tahun, oleh karena itu 
sekalipun batita diasuh selain ibu akan tetapi pola pemberian makannya baik.

Hubungan pengasuh selain ibu dengan batita rata-rata yaitu sebagai nenek sebesar $59,5 \%$. Penelitian Puspita memaparkan bahwa pengasuh pengganti paling banyak yaitu nenek, karena dianggap banyak pengalamannya dalam merawat anak dan orang kepercayaan ibu, nenek juga menerapkan pola pemberian makan yang baik pada balita ${ }^{24}$. Berdasarkan hasil penelitian tersebut maka diperlukan peningkatan sosialisasi mengenai pentingnya penerapan pola pemberian makan yang baik bagi batita, karena sekalipun rata-rata pola pemberian makan pengasuh terhadap batita sudah tepat, akan tetapi masih ada yang belum tepat. Pola pemberian makan yang salah akan berdampak pada masalah status gizi batita.

\section{KESIMPULAN}

Tidak ada perbedaan pola pemberian makan antara batita yang diasuh ibu dan batita yang diasuh selain ibu, hal ini dikarenakan pola pemberian makan faktor yang mempengaruhi pola pemberian makan tidak hanya penanggungjawab mengasuh batita setiap harinya, akan tetapi dipengaruhi berbagai faktor seperti tingkat pendidikan ibu batita, tingkat pendapatan keluarga, jumah anggota keluarga, usia pengasuh serta status hubungan pengasuh dengan batita, karena sebagian besar sebagai nenek yang sudah berpengalaman dalam hal merawat batita, maka pola pemberian makan dalam kategori tepat.

Saran yang diberikan yaitu meningkatkan pengetahuan gizi pengasuh batita mengenai pentingnya pola pemberian makan yang tepat bagi batita dengan menggiatkan penyuluhan di Posyandu melalui program rutin Puskesmas Muyorejo Surabaya, karena sekalipun pola pemberian makan sebagian besar dalam kategori baik, akan tetapi masih ada yang kurang optimal, sehingga masalah gizi bisa diminimalisir.

\section{ACKNOWLEDGEMENT}

Penulis mengucapkan terima kasih kepada pihak instansi Puskesmas Mulyorejo
Surabaya dan seluruh ibu kader yang telah membantu dalam pengambilan data di lapangan.

\section{REFERENSI}

1. Saputra F, Hasanah O, Sabrian F. Perbedaan Tumbuh Kembang Anak Toddler Yang Diasuh Orang Tua Dengan Yang Dititipkan Ditempat Penitipan Anak (TPA). JOM . 2015; 2(2): 1123-1130.

2. Katalog Badan Pusat Statistik. 2015. Statistik Indonesia 2015. Badan Pusat Statistik. Indonesia.

3. Katalog Badan Pusat Statistik. Jawa Timur Dalam Angka 2015. Badan Pusat Statistik Provinsi Jawa Timur. 2015

4. Badan Pusat Statistik. 2014. Kecamatan Mulyorejo Dalam Angka 2014. Badan Pusat Statistik Kota Surabaya

5. Sulistyorini E,Rahayu T. Hubungan Pekerjaan Ibu Balita Terhadap Status Gizi Balita Di Posyandu Prima Sejahtera Desa Pandean Kecamatan Ngemplak Kabupaten. Jurnal Kebidanan Indonesia. 2009; 1(2): 92-102.

6. Kusumanti, DP, Zulaicha, NE. Hubungan Status Pekerjaan Dengan Motorik Kasar Pada Balita Di Desa Kaligono. Jurnal Komunikasi Kesehatan. 2014; 6 (2)

7. Azizah NN. Perbandingan Tumbuh Kembang Anak Toddler Yang Diasuh Orang Tua Dengan Diasuh Selain Orang Tua. Skripsi. Universitas Indonesia. Depok Jawa Barat. 2012.

8. Fristi W, Indriati G, Erwin. Perbandingan Tumbuh Kembang Anak Toddler Yang Diasuh Orang Tua Dengan Diasuh Selain Orang Tua. Jurnal Online Mahasiswa Bidang Ilmu Keperawatan. 2014; 1(2)

9. Wijaya M D. Perbedaan Status Gizi Batita (1-3 Tahun)Yang Diasuh Ibu Dengan Yang Diasuh Pembantu Rumah Tangga Di Posyandu Kemala Kelurahan Barusari Kecamatan Semarang Selatan Kota Semarang. Skripsi. Universitas Negeri Semarang. 2009.

10. Putri FR, Sulastri D, Lestari Y. FaktorFaktor Yang Berhubungan Dengan Status Gizi Anak Balita Di Wilayah Kerja Puskesmas Nanggalo Padang. Jurnal Kesehatan Andalas. 2015; 4(1): 254-261 
11. Badan Pusat Statistik. Kecamatan Mulyorejo Dalam Angka 2016. Badan Pusat Statistik Kota Surabaya. 2016.

12. Adriani M, Wirjatmadi B. Peranan Gizi Dalam Siklus Kehidupan. Jakarta: Kencana; 2012.

13. Wijono D. Manajemen Perbaikan Gizi Masyarakat. Surabaya: Duta Prima Airlangga; 2009.

14. Sulistyoningsih H. Gizi Untuk Kesehatan Ibu Dan Anak. Graha Ilmu: Yogyakarta; 2011. p. 52-56.

15. Notoatmodjo S. Metodologi Penelitian Kesehatan. Jakarta : Rineka Cipta; 2010.

16. Pratiknya AW. Dasar-Dasar Metodologi Penelitian Kedokteran dan Kesehatan. Jakarta: PT Raja Grafindo Persada; 2000.

17. Chelule $P$, Chihope CN. Feeding Practices Among The Child Caregivers Of 5 Year-Old Children Attended To For Acute Malnutrition At Nyangabgwe Hospital, Botswana. Botswana Journal of African Studies. 2014; 28 (1): 13-27.

18. Suiraoka P, Sukraniti PD, Gumala YMN. Perbedaan Status Gizi, Pola Pemberian Makan, Dan Pola Asuh Balita Pada Keluarga Miskin Dan Tidak Miskin Di Kecamatan Denpasar Utara, Kota Denpasar. Jurnal Ilmu gizi. 2011; 2(2): 8392.

19. Kumala M. Hubungan Pola Pemberian Makan Dengan Status Gizi Anak Usia
Toddler (1-3 Tahun) Di Posyandu Kelurahan Sidomulyo Godean Sleman 2013. Naskah Publikasi. Sekolah Tinggi Ilmu Kesehatan 'Aisyiyah Yogyakarta. 2013.

20. Kurniasari E, Nurzina R, Mulyani EY. Perbedaan Status Gizi Balita Usia 12-36 Bulan Berdasarkan Pola Asuh dan Status Pekerjaan Ibu di Wilayah Kerja Puskesmas Jatimulya Kabupaten Bekasi Tahun 2016. Jurnal Online Mahasiswa. 2016; 1(2): 8594.

21. Kementerian Kesehatan RI. Pedoman Gizi Seimbang 2014. Jakarta: Ditjen Bina Gizi dan Kesehatan Ibu dan Anak. 2014.

22. Tessema MEG, Belachew T. Feeding Patterns And Stunting During Early Childhood In Rural Communities of Sidama, South Ethiopia. Pan Africa Medical Journal. 2013; 75(14): ISSN 19378688

23. Sukoco NEW, Pambudi J, Herawati MH. Hubungan Status Gizi Anak Balita Dengan Orang Tua Bekerja. Buletin Penelitian Sistem Kesehatan. 2015: 18(4); 387-397.

24. Puspita DF. Sumber Daya Pengasuhan Dan Status Gizi Balita Pada Ibu Bekerja Di Wilayah Kerja Puskesmas Simolawang Kecamatan Simokerto Surabaya. Skripsi. Universitas Airlangga Surabaya. 2012 